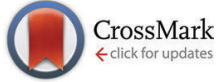

Cite this: Phys. Chem. Chem. Phys., 2015, 17, 30481

Received 18th May 2015, Accepted 22nd October 2015 DOI: $10.1039 / c 5 c p 01132 a$

www.rsc.org/pccp

\section{Structure and dynamics of aqueous 2-propanol: a THz-TDS, NMR and neutron diffraction study $\dagger$}

\author{
James McGregor, $\ddagger^{*^{a}}$ Ruoyu Li, ${ }^{a}$ J. Axel Zeitler, ${ }^{a}$ Carmine D'Agostino, ${ }^{a}$ \\ James H. P. Collins, ${ }^{a}$ Mick D. Mantle, ${ }^{a}$ Haresh Manyar, ${ }^{b}$ John D. Holbrey, ${ }^{b}$ \\ Marta Falkowska, ${ }^{b}$ Tristan G. A. Youngs, $\S^{c}$ Christopher Hardacre, ${ }^{b}$ E. Hugh Stitt ${ }^{d}$ \\ and Lynn F. Gladden ${ }^{a}$
}

\begin{abstract}
Aqueous liquid mixtures, in particular, those involving amphiphilic species, play an important role in many physical, chemical and biological processes. Of particular interest are alcohol/water mixtures; however, the structural dynamics of such systems are still not fully understood. Herein, a combination of terahertz time-domain spectroscopy (THz-TDS) and NMR relaxation time analysis has been applied to investigate 2-propanol/water mixtures across the entire composition range; while neutron diffraction studies have been carried out at two specific concentrations. Excellent agreement is seen between the techniques with a maximum in both the relative absorption coefficient and the activation energy to molecular motion occurring at $\sim 90 \mathrm{~mol} \% \mathrm{H}_{2} \mathrm{O}$. Furthermore, this is the same value at which wellestablished excess thermodynamic functions exhibit a maximum/minimum. Additionally, both neutron diffraction and THz-TDS have been used to provide estimates of the size of the hydration shell around 2-propanol in solution. Both methods determine that between 4 and $5 \mathrm{H}_{2} \mathrm{O}$ molecules per 2-propanol are found in the 2-propanol/water clusters at $90 \mathrm{~mol} \% \mathrm{H}_{2} \mathrm{O}$. Based on the acquired data, a description of the structure of 2-propanol/water across the composition range is presented.
\end{abstract}

\section{Introduction}

Aqueous solutions of alcohols have provided a rich seam for scientific research for many years. Such binary mixtures are ubiquitous in many fields, including fuel cell technology and bioscience. ${ }^{1-4}$ In the latter field, alcohols also serve as model compounds for more complex amphiphiles such as proteins, with the influence of the solute on the structure of water being of significant interest. Elsewhere, alcohol/water mixtures are employed as solvents for chemical processes, including catalytic reactions, with 2-propanol/water systems of particular interest.

\footnotetext{
${ }^{a}$ Department of Chemical Engineering and Biotechnology, University of Cambridge, Cambridge CB2 3RA, UK. E-mail: james.mcgregor@sheffield.ac.uk

${ }^{b}$ School of Chemistry and Chemical Engineering, Queen's University Belfast, Belfast BT9 5AG, UK

${ }^{c}$ School of Mathematics and Physics, Queen's University Belfast, Belfast BT9 5AG, $U K$

dJohnson Matthey Catalysts, P.O. Box 1, Belasis Avenue, Billingham, Cleveland TS23 1LB, UK

$\dagger$ Electronic supplementary information (ESI) available. See DOI: 10.1039/ c5cp01132a

\$ Present address: Department of Chemical and Biological Engineering University of Sheffield, Sheffield S1 3JD, UK.

$\S$ Present address: ISIS Neutron and Muon Source, Science and Technology Facilities Council, Rutherford Appleton Laboratory, Harwell Oxford, Didcot OX11 0QX, UK.
}

A parallel and complementary work specifically explores the role of aqueous 2-propanol as a solvent in the heterogeneous catalytic hydrogenation of 2-butanone. ${ }^{5}$ In the present contribution we report an investigation of the structure and dynamics of 2-propanol/ water mixtures, with the aim of contributing to a better understanding of the molecular-scale processes occurring in such systems. To this end we have employed nuclear magnetic resonance (NMR) spectroscopy, neutron scattering combined with empirical potential structure refinement (EPSR) analysis and terahertz time-domain spectroscopy (THz-TDS). THz-TDS allows access to the fast (ps and sub-ps) processes which take place within aqueous mixtures. The methodology presented is relevant to a wide range of liquid systems.

\subsection{Background}

It is well established that upon mixing, aqueous alcohol solutions display anomalous transport and thermodynamic behaviour, such as a less than expected increase in entropy. Excess functions are also observed for other thermodynamic properties: free energy and enthalpy. For 2-propanol/water mixtures at $303 \mathrm{~K} \mathrm{a}$ maximum negative excess enthalpy is observed at $\sim 90 \mathrm{~mol} \%$ $\mathrm{H}_{2} \mathrm{O}$. ${ }^{6}$ The observed maxima in the thermodynamic functions are co-incidental with maxima and minima in the physical properties of such mixtures. For instance, the viscosity of alcohol/water mixtures achieves a maximum, ${ }^{7,8}$ with a corresponding minimum 
for the diffusion coefficient. ${ }^{9}$ Despite the apparent simplicity of alcohol/water systems there has been much debate as to the physical basis of these effects. ${ }^{10}$ However, a consensus has now emerged supporting the view that it is the hydrogen bond (HB) dynamics, and, therefore, the dynamical structure of the solutions, that are the origin of these phenomena. ${ }^{10-15}$

The earliest analyses, including the seminal work by Frank and Evans, ${ }^{16}$ proposed that the origin of the anomalous effects observed upon mixing alcohols and water was a consequence of the water structure becoming "enhanced", or more "ice-like" in the presence of a hydrophobic entity such as the alkyl group of an alcohol. Neutron diffraction studies, however, have demonstrated that there is no need to invoke such an "iceberg theory". Instead, taking methanol/water mixtures as a representative example, the excess thermodynamic properties may be explained as arising from incomplete mixing on the molecular level. ${ }^{12,17}$ Dougan and co-workers have demonstrated that around the composition where excess thermodynamic properties are at their maxima, methanol and water form separate, bi-percolating liquid-networks. ${ }^{18}$ Furthermore, from simulations based on experimental neutron diffraction data it has been demonstrated that the excess entropy associated with water/methanol mixtures, and the dependence of this on composition, can be quantitatively explained through this segregation of methanol and water at the molecular level. ${ }^{19}$ The lifetime of the methanol and water clusters formed is on average $3 \mathrm{ps}$, indicating that the origin of these effects is indeed dynamical. Recently, Artola et al., have applied a range of techniques including neutron diffraction and NMR to water/2-methyl-2-propanol mixtures, identifying hydrogen bonding as the driving force behind the observed mesoscopic structural organisation. ${ }^{20}$ Elsewhere Juurinen and co-workers have employed X-ray Raman scattering to interrogate water/ alcohol mixtures for a range of short-chained alcohols. ${ }^{21}$

\subsection{THz-TDS studies}

THz-TDS is ideally suited to the study of HB dynamics as such processes occur on the picosecond timescale. Such short timescales are readily probed by THz-TDS. Aqueous solutions of methanol, acetone and acetonitrile have previously been studied using THz spectroscopy by Venables et al. ${ }^{11,22}$ The non-ideality of such solutions was readily apparent from the acquired terahertz spectroscopy data, with an enhancement in structure observed relative to the individual components. Additionally, the dynamical HB breaking/forming processes occurring on ps timescales were quantitatively identified. Such systems bear a close resemblance to the 2-propanol/water mixtures studied in the present work. More recently we have applied THz-THS to the study of mesoscopic structuring in aqueous solutions of primary alcohols. ${ }^{15}$ This work identified critical compositions corresponding to changes in the hydrogen-bonding structure of the mixtures. Considering proton transfer in aqueous solutions, Tielrooij et al. have employed THz-TDS to demonstrate that a large number of water molecules are involved in such processes, thereby indicating that such a mechanism is likely to be limited to situations where a large excess of water molecules is present. ${ }^{23}$ Elsewhere, aqueous solutions of biologically relevant molecules, and in particular their hydration, has been the subject of study. ${ }^{4,24-29}$

\subsection{NMR studies}

NMR measurements, like terahertz spectroscopy, have also previously been employed to study aqueous solutions of alcohols. Corsaro and co-workers performed ${ }^{1} \mathrm{H}$ NMR experiments in which the spin-lattice $\left(T_{1}\right)$ and spin-spin $\left(T_{2}\right)$ relaxation times were measured for methanol/water mixtures. ${ }^{1}$ These measurements supported the conclusion that the thermodynamic properties of these mixtures are governed by HB dynamics, with the lifetime and stability of HBs being dependent upon the liquid composition. Additionally, the results were consistent with the presence of local clusters at temperatures above $245 \mathrm{~K}$. Elsewhere, an analysis of the rotational correlation time of water molecules around benzene based on $T_{1}$ measurements has demonstrated that rotational dynamics are correlated with HB strength. Water molecules in the hydration shell of benzene were concluded to form stronger HBs and to have slower correlation times than those in the bulk water phase. ${ }^{30}$ Measurements of diffusion times using PFG NMR related these results to translation motions. PFG NMR has also been applied alongside THz-TDS to measure diffusion coefficients in binary primary alcohol/water systems correlating a minimum in the measured diffusivity with the formation of extended alcohol-water networks. $^{15}$

In the present work NMR relaxation time analysis has been conducted to support THz-TDS studies. Specifically, ${ }^{1} \mathrm{H}$ NMR relaxation time analysis has been employed to determine the activation energy for the alkyl group of 2-propanol to undergo a molecular diffusive jump. ${ }^{31,32} T_{1}$ is correlated to the motional correlation time, $\tau_{\mathrm{c}}$, and hence a measurement of $T_{1}$ reveals information on the motion and reorientation of the molecules under study, i.e. a change in their interaction with neighbouring molecules. ${ }^{33}$ This process is indicated schematically in Fig. 1.

\subsection{Neutron diffraction studies}

Neutron diffraction techniques have not previously been employed in structural investigations of 2-propanol/water mixtures, however, their applicability for such studies is evident from previous investigations on both single-component liquids: water, methanol, ethanol and 2-propanol; and binary methanol/water, ethanol/water

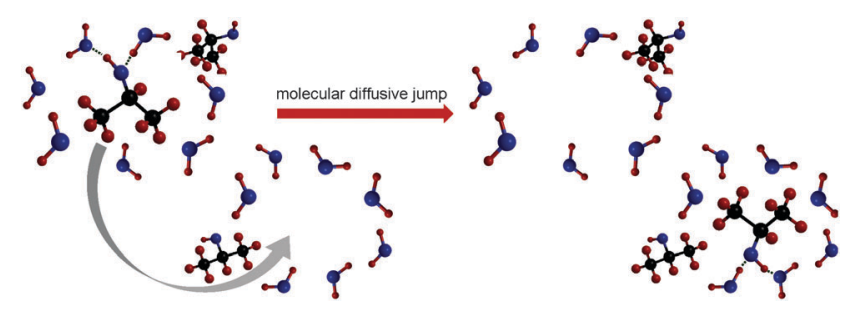

Fig. 1 Schematic of an example of the process referred to in the text as a "molecular diffusive jump". This involves a 2-propanol molecule changing its interaction with neighbouring molecules in solution; a process which can be probed by NMR relaxation time analysis. Both rotational and translation motions play a role in this process. 
and 2-methyl-2-propanol/water mixtures. ${ }^{20,34-37}$ Misawa et al. have studied 1-propanol/water mixtures using SANS in the low $Q$ region combined with large-scale reverse Monte Carlo (RMC) analysis of the data and describe the mesoscale structure of the liquids in terms of polydispersed water and alcohol clusters in which most of the molecules reside at interfaces between the clusters; however, no direct atomistic information can be extracted from these data. ${ }^{38}$ Tanaka et al. performed a neutron diffraction study of deuterated methanol and determined the geometry of molecules within the liquid. $^{34} \mathrm{O}-\mathrm{D}, \mathrm{C}-\mathrm{O}$ and $\mathrm{C}-\mathrm{D}$ bond lengths of $0.990 \pm 0.010$, $1.435 \pm 0.005$ and $1.085 \pm 0.005 \AA$, respectively, were established. Zetterstrom et al. investigated the structure of 2-propanol by neutron diffraction ${ }^{35}$ and the bond lengths obtained were found to be in good agreement with those reported for methanol and ethanol. ${ }^{36}$ More recently, Takamuku and co-workers combined X-ray and neutron scattering studies to investigate the structure of methanol, methanol/water and ethanol/water mixtures. ${ }^{37}$ For the alcohol/water mixtures, the tetrahedral-like structure of water was predominant at $\geq 90 \mathrm{~mol} \% \mathrm{H}_{2} \mathrm{O}$, whilst water and alcohol clusters coexist in the mixtures from $\sim 90-\sim 30 \mathrm{~mol} \% \mathrm{H}_{2} \mathrm{O}$. Below $30 \mathrm{~mol} \%$ $\mathrm{H}_{2} \mathrm{O}$ alcohol clusters are predominant. Dixit and co-workers have studied methanol/water mixtures using neutron diffraction and showed that most of the water molecules exist as small hydrogen bonded clusters surrounded by close-packed methyl groups, with water clusters bridging neighbouring methanol hydroxyl groups through hydrogen bonding. ${ }^{17}$ Investigating more hydrophobic alcohols, Bowron and co-workers have shown how addition of even small quantities of water perturbs the liquid structure of tertiary butanol through preferential hydrogen-bonding of the alcohol $\mathrm{OH}$-group to water. ${ }^{39-41}$

\section{Experimental}

THz-TD and NMR spectroscopy measurements have been conducted across the entire 2-propanol/water composition range, while small angle neutron scattering data have been collected on sets of H/D isotopically substituted 2-propanol/water mixtures at two representative compositions of 70 and $90 \mathrm{~mol} \% \mathrm{H}_{2} \mathrm{O}$.

\subsection{THz time-domain spectroscopy}

2.1.1 Apparatus. Sub-picosecond coherent pulses of broadband terahertz radiation ( 0.1 to $4 \mathrm{THz})$ were generated by photoexcitation of a DC biased semi-insulating GaAs substrate by 12 fs pulses of a NIR laser (Femtolasers, Femtosource cM1, Vienna, Austria, centre wavelength $800 \mathrm{~nm}$ ), as described previously. ${ }^{43}$ In order to suppress the absorption of water vapour in the air, the sealed sample chamber was purged with nitrogen gas to ensure a relative humidity below $2 \%$ for all measurements. Liquid samples were measured in a standard cell (PIKE Technologies, Watertown, USA) comprising $3 \mathrm{~mm}$ z-cut quartz windows and a $200 \mu \mathrm{m}$ PTFE spacer. For each sample 200 time-domain waveforms were collected and averaged. The temperature was held constant at $303 \pm 1 \mathrm{~K}$.

2.1.2 Analysis of dielectric relaxation. The dielectric spectra of 2-propanol/water mixtures have been fitted according to a previously described $^{15}$ three-component Debye model. This three-component model is described by eqn (1):

$$
\varepsilon_{\text {Debye }}=\varepsilon_{\infty}+\frac{\varepsilon_{1}}{1+i \omega \tau_{1}}+\frac{\varepsilon_{2}}{1+i \omega \tau_{2}}+\frac{\varepsilon_{3}}{1+i \omega \tau_{3}}
$$

where $\omega$ denotes the angular frequency and $\varepsilon_{\infty}$ is the optical dielectric constant; $\varepsilon_{i}$ and $\tau_{i}$ are the relaxation strength and dielectric relaxation time of the $i$ th Debye relaxation component.

As described in our earlier work (conducted at $293 \mathrm{~K}$ as opposed to at $303 \mathrm{~K}$ in the present study), ${ }^{15}$ in our analysis, $\tau_{1}$ and $\tau_{2}$ were constrained to the values of the relaxation times of pure water and pure 2-propanol; these values were determined to be 7.6 and $26.6 \mathrm{ps}$, respectively, at $303 \mathrm{~K}$. The relaxation strengths $\varepsilon_{1}$ and $\varepsilon_{2}$ are then assumed to represent the relative number of molecules present within the respective structural domains. As discussed by Li et al., ${ }^{15}$ whilst the interpretation of $\varepsilon_{1}$ is as a measure of the number of water molecules present, $\varepsilon_{2}$ is taken to represent both the bulk alcohol and alcohol-water mixtures. $\varepsilon_{3}$ and $\tau_{3}$ are associated with the femtosecond relaxation component which has been considered to be associated with the fast process of hydrogen bond formation and decomposition. ${ }^{11,22}$ The relaxation strength of the femtosecond term is extremely small and, therefore, discussion is focussed only on the two picosecond terms. It should be noted that three modes have previously been identified in the dielectric relaxation spectrum of pure 2-propanol, ${ }^{14,44}$ and that some previous work has employed two-component models to analyse aqueous solutions. ${ }^{11,22}$ It is, therefore, important to note that the aim of this work is not to determine absolute relaxation times $(\tau)$, but to use this parameter to separate the spectral response into distinct domains with different physical properties characterised by their relaxation strength $(\varepsilon)$. Further details of this approach are provided by Li et al. ${ }^{15}$

\subsection{NMR relaxation time analysis}

The activation energy to a molecular reorientation, or diffusive jump, ${ }^{32,45}$ has been evaluated in this work by conducting measurements of $T_{1}$ at a series of temperatures, followed by the application of an Arrhenius-type expression:

$$
\frac{1}{T_{1}}=\exp \left(\frac{E_{\mathrm{a}}}{R T}\right)
$$

where $E_{\mathrm{a}}$ is the activation energy towards a molecular diffusive jump, $R$ is the ideal gas constant and $T$ is temperature. These measurements have focussed on the alkyl group of 2-propanol. Relatively little data, in comparison to that concerned with $-\mathrm{OH}$ moieties, have been published focusing on the behaviour of the alkyl group despite the role that this plays in determining liquid structure. ${ }^{46}$ The alkyl functionality is particularly attractive for NMR studies as it allows for ready discrimination between water and 2-propanol and does not suffer from problems associated with ${ }^{1} \mathrm{H}$-exchange between the two components. Elsewhere, this methodology has been applied to probe adsorbate-adsorbent interactions. ${ }^{32}$ In that work, the strength of interaction between adsorbate and adsorbent was described by the difference between 
the activation energies for molecular diffusive jumps in the liquid phase and for molecular motion on the adsorbent surface.

Measurements of $T_{1}$ between $298-343 \mathrm{~K}$ were carried-out as follows: NMR measurements were conducted using a Diff30 diffusion probe with a $10 \mathrm{~mm}$ r.f. coil on a Bruker DMX 300 spectrometer, operating at a ${ }^{1} \mathrm{H}$ resonance frequency of 300.13 MHz. After heating to the desired temperature, $20 \mathrm{~min}$ was allowed prior to measurement to ensure thermal equilibrium. Temperature stability was $\pm 1 \mathrm{~K} . T_{1}$ was measured using a standard inversion-recovery pulse sequence. ${ }^{47}$ The $90^{\circ}$ and $180^{\circ}$ pulse lengths were $10 \pm 1 \mu$ s and $20 \pm 2 \mu$ s, respectively. The precise pulse lengths vary with temperature and chemical system under study, hence the exact $90^{\circ}$ and $180^{\circ}$ pulse lengths were calibrated for each sample at each temperature studied.

\subsection{Neutron diffraction}

Neutron-scattering data were collected using SANDALS at the ISIS pulsed neutron and muon source at the Rutherford Appleton Laboratory, UK. The instrument has a wavelength range of 0.05 to $4.5 \AA$, and data were collected over a $Q$ range of 0.1 to $50 \AA^{-1}$. Each sample was contained in "null scattering" $\mathrm{Ti}_{0.68} \mathrm{Zr}_{0.32}$ flat plate cells with internal geometries of $1 \times 35 \times 35 \mathrm{~mm}$, with a wall thickness of $1 \mathrm{~mm}$. During measurements, the samples were maintained at a temperature of $298 \mathrm{~K}$ using a recirculating Julabo FP50 water bath. Measurements were made on each of the empty sample holders, the empty spectrometer, and a $3.1 \mathrm{~mm}$ thick vanadium standard sample for the purposes of data normalisation.

Data were collected from five isotopically-substituted 2-propanol/ water mixtures (2-propanol/ $\mathrm{D}_{2} \mathrm{O}, 2$-propanol- $d_{8} / \mathrm{H}_{2} \mathrm{O}$, 2-propanol$d_{8} / \mathrm{D}_{2} \mathrm{O}, 2$-propanol- $d_{6} / \mathrm{D}_{2} \mathrm{O}, 2$-propanol $\left./ \mathrm{H}_{2} \mathrm{O}\right)$ at 70 and $90 \mathrm{~mol} \%$ water, and five neat 2-propanol samples (2-propanol- $d_{8}$, 2-propanol- $d_{6}, 2$-propanol, and 2-propanol- $d_{8} / 2$-propanol in $2: 1$ and $1: 2$ ratios).

Data analysis was performed using GUDRUN, ${ }^{48,49}$ to produce a differential scattering cross section for each sample. The experimental sample densities and scattering levels were consistent with the actual isotopic compositions of the samples. Analysis of the data proceeded via refinement of atomistic models of the target systems using EPSR, ${ }^{50-52}$ and all quantities were calculated using either EPSR or dlputils. ${ }^{53}$ This refinement consists of a Monte Carlo simulation using Lennard-Jones potentials with atom-centred point charges comparing the residuals from the simulated data with experimental values in $Q$-space. The simulating process combines these data with basic information about the structure of the compounds and total atomic densities of the system to constrain the simulation in a chemically and physically reliable manner. The experimental total structure factors, $F(Q)$, were measured for each of the five isotopically distinct samples at each composition.

The EPSR refinements were initialised using equilibrated Monte Carlo simulations at $298 \mathrm{~K}$ containing 500 molecules in a cubic box of sides $39.97,27.11$, and $30.58 \AA$ for the neat 2-propanol, 90 and $70 \mathrm{~mol} \%$ systems, respectively. These correspond to atomic densities of 0.0940, 0.0979, and 0.0997 atoms $\AA^{-3}$, derived from the experimentally determined molecular densities of the fully protiated liquids. Atom types and parameters for the reference potential used in EPSR were taken from the OPLS-AA ${ }^{54}$ and $\mathrm{SPC} / \mathrm{E}^{55}$ force fields (see ESI, $\dagger$ Table S1).

\section{Results}

\subsection{THz-TDS}

The absorption coefficients, $\alpha$, of 2-propanol/water mixtures were calculated according to the Beer-Lambert law. At all concentrations a monotonic increase in $\alpha$ with frequency is observed. The variation in $\alpha$ with composition provides a measurement of the structural differences between solutions on the molecular level. Fig. 2 shows how $\alpha$, determined at a frequency of $1 \mathrm{THz}$, changes with composition. Data at other frequencies also show the same trend. It is clear that a rapid increase in $\alpha$ is observed for water concentrations in excess of $\sim 90 \mathrm{~mol} \% \mathrm{H}_{2} \mathrm{O}$.

The concentration dependence of the complex dielectric spectra determined in the $\mathrm{THz}$ region are shown in Fig. 3. Dielectric relaxation analysis of the $\mathrm{THz}$ spectroscopy data has been carried out in order to differentiate between the different structural domains present in the mixtures. Fig. 4(a) shows the theoretical variation of relaxation strength $(\varepsilon)$ with composition if the only domains present were bulk water and bulk 2-propanol structures, i.e. the ideal case in which no interactions between alcohol and water molecules and consequently no 2-propanol/water networks exist. Fig. 4(b) shows the data derived from the experimental system. While the relaxation times of components 1 and 2 were fixed to the experimentally derived values of $\tau_{\text {water }}=7.6 \mathrm{ps}$ and $\tau_{2 \text {-propanol }}=26.6 \mathrm{ps}$, respectively, the third component was a free variable and was determined to have a characteristic relaxation time $(\tau)$ of the order of femtoseconds, ranging from a minimal value of 107 fs (pure water) to a maximum of $161 \mathrm{fs}\left(15 \mathrm{~mol} \% \mathrm{H}_{2} \mathrm{O}\right)$, as shown in Table S2 (ESI $\dagger$ ). Table S2 (ESI $\dagger$ ) indicates the dielectric relaxation parameters obtained through fitting the model. This approach follows the methodology introduced by Li et al. and further details can be found therein. ${ }^{15}$ This fs term can be assigned to the fast small rotations and translations of individual molecules or small, highly local structures. ${ }^{56-58}$ Due to the small relative relaxation strength of $\varepsilon_{3}$ as compared to $\varepsilon_{1}$ and $\varepsilon_{2}$, the number of molecules with this relative relaxation strength is treated as negligible in the following discussions. ${ }^{15,57}$

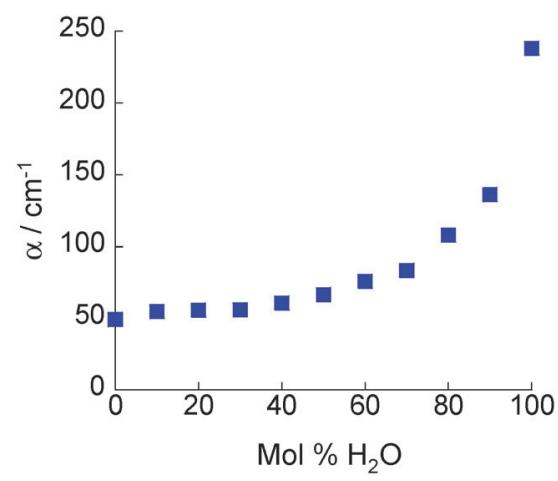

Fig. 2 Absorption coefficient of 2-propanol/water mixtures at $1 \mathrm{THz}$. 
a)

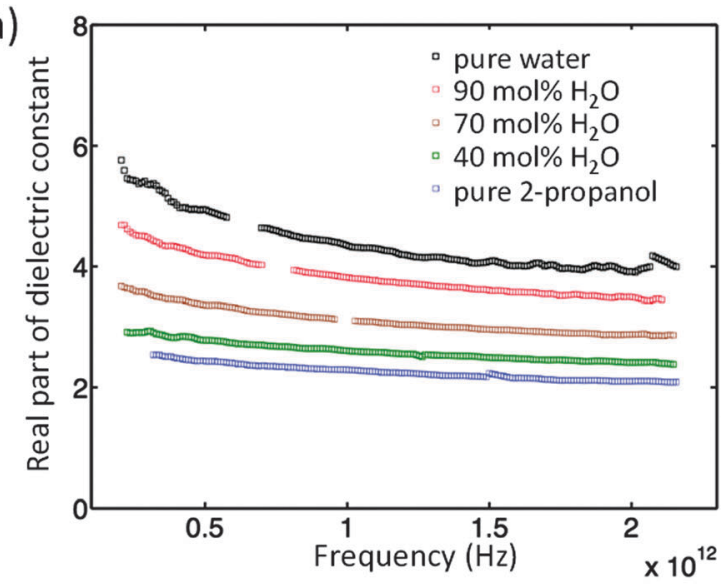

b)

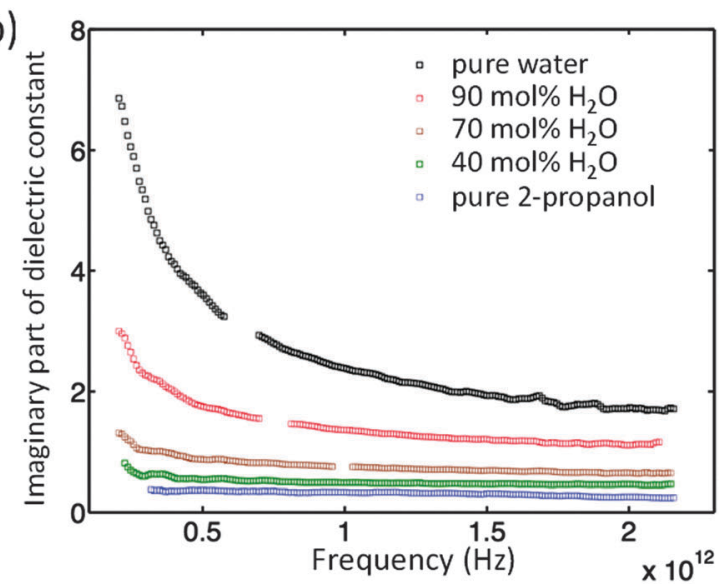

Fig. 3 Complex dielectric spectra of 2-propanol/water mixtures at $100,90,70,40$ and 0 mol\% $\mathrm{H}_{2} \mathrm{O}$. a)

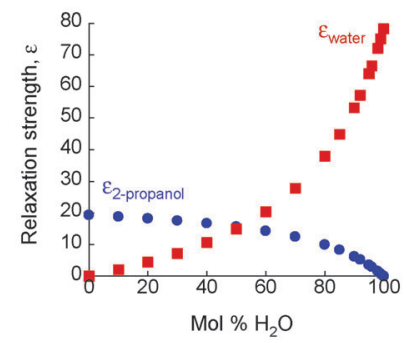

b)

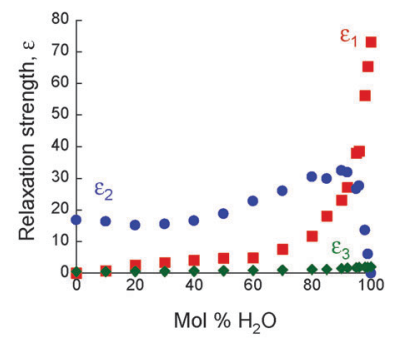

Fig. 4 (a) The relative relaxation strength of bulk water: $\varepsilon_{\text {water }}(\boldsymbol{\square})$ and bulk 2-propanol: $\varepsilon_{2 \text {-propanol }}(\mathbf{0})$ based on the ideal non-interacting model described in the text. (b) The relative relaxation strength of the three components in eqn (1): $\varepsilon_{1}(\boldsymbol{\square}), \varepsilon_{2}(\bullet)$ and $\varepsilon_{3}(\bullet)$ from experimental THzTDS measurements.

When comparing the results from the three-component Debye model (Fig. 4b) with the results from the noninteracting model (Fig. 4a) it is seen that $\varepsilon_{1}$ is lower than $\varepsilon_{\text {water }}$ over the entire concentration range. As the relaxation time for this component was fixed as $\tau_{\text {water }}$, this indicates the presence of 2-propanol/water networks in the mixture; thereby reducing the number of water molecules existing as bulk water. The assignment of $\varepsilon_{2}$ as representing the amount of both bulk alcohol and alcoholwater structures arises from the observation that $\varepsilon_{2}$ takes higher values than the ideal values, $\varepsilon_{2 \text {-propanol }}$, derived from the noninteracting model, with a maximum at $\sim 90 \mathrm{~mol} \% \mathrm{H}_{2} \mathrm{O}$. As described previously, ${ }^{15}$ and in line with the results of other workers, it is recognised that in alcohol-rich mixtures the picosecond contributions from pure alcohol and alcohol-water networks are indistinguishable in the $\mathrm{THz}$ data. Therefore, through an examination of the difference between the calculated value of $\varepsilon_{2 \text {-propanol }}$ and the measured value of $\varepsilon_{2}$, the structural changes occurring in 2-propanol/water mixtures become apparent. At low water concentrations the system is dominated by bulk 2-propanol structures with little or no bulk water structures present. This implies that most of the available water molecules are involved in 2-propanol/water networks. As the water concentration increases, bulk water structures emerge, with all three distinct structural domains co-existing. The number of alcohol and water molecules associated with 2-propanol/water networks increases as the number of water molecules increases (as inferred from Fig. 4, where $\varepsilon_{2}>$ $\varepsilon_{2 \text { propanol }}$ and $\varepsilon_{1}<\varepsilon_{\text {water }}$ ) reaching a maximum at $\sim 90 \mathrm{~mol} \%$ $\mathrm{H}_{2} \mathrm{O}$. Above this value, little or no bulk-like 2-propanol remains; instead the alcohol molecules present are associated with water molecules. Therefore, this indicates that 2-propanol/ water networks exist across the entire composition range. The presence of significant 2-propanol/water networks is consistent with previous small angle neutron scattering data acquired at $0.87 \mathrm{~mol} \% \mathrm{H}_{2} \mathrm{O}^{59}$ and with calculations based on the KirkwoodBuff model which confirm alcohol-water clustering at high water concentrations..$^{60}$ It is also noteworthy that it is only at these high water concentrations that a significant excess of bulk-like water exists, and, therefore, that efficient proton transfer will occur. ${ }^{23}$

Dielectric relaxation analysis has confirmed the presence of 2-propanol/water clusters and by extension the non-ideal nature of the solutions. Alcohol/water mixtures are well known to mix non-ideally, with the extent of the deviation from ideality being quantified through parameters such as excess thermodynamic functions. ${ }^{6}$ This "excess" is with regard to what would be expected from an ideal solution. In the same manner, the absorption coefficient as measured by THz-TDS deviates from that expected from an ideal solution. In order to quantify this deviation, the absorption relative to an ideal mixture was calculated. This is defined as the deviation of the measured absorption coefficients from the calculated values. The calculated values are based on measurements of single-component liquids and the non-interacting binary model, as shown in eqn (3) and (4):

$$
\alpha_{\text {ideal }}(\omega)=\rho_{\text {real }} / \rho_{\text {ideal }}\left[V_{\text {water }} \alpha_{\text {water }}(\omega)+V_{\text {ipa }} \alpha_{\text {ipa }}(\omega)\right]
$$

$$
\alpha_{\text {relative }}=\alpha_{\text {ideal }}-\alpha_{\text {real }}
$$

where $\alpha$ is the adsorption coefficient, $\rho$ is density, $V$ is volume and $\omega$ is the angular frequency. The density ratio factor in eqn (3) accounts for small non-idealities in the volume of mixing. Fig. 4(a) shows the relative absorption coefficient of 
2-propanol/water mixtures at $303 \mathrm{~K}$ at a frequency of $1 \mathrm{THz}$. Data at other frequencies follow the same trend.

Fig. 5(a) shows the change in relative absorption coefficient as a function of composition in the 2-propanol/water mixtures. It is clear that at all compositions, the absorption coefficient of the real mixture is lower than that of the ideal mixtures. The extent of this difference, i.e. $\alpha_{\text {ideal }}-\alpha_{\text {real }}$ or relative absorption coefficient, has previously been shown to correlate with rotational dynamics and structuring in liquids. ${ }^{11,15,22}$ A greater relative absorption coefficient indicates more retarded rotational dynamics and an increase in the structuring of extended hydrogen-bonded networks between alcohol and water molecules. 2-Propanol/water mixtures, therefore, exhibit greater structure than an ideal solution, as would be expected from the wellestablished excess thermodynamic properties of this mixture, with a maximum occurring at $\sim 90 \mathrm{~mol}^{\circ} \mathrm{H}_{2} \mathrm{O}$.

\subsection{NMR measurements}

3.2.1 Relaxation time analysis: activation energies. Fig. 5(b) shows the activation energy for 2-propanol to undergo a molecular
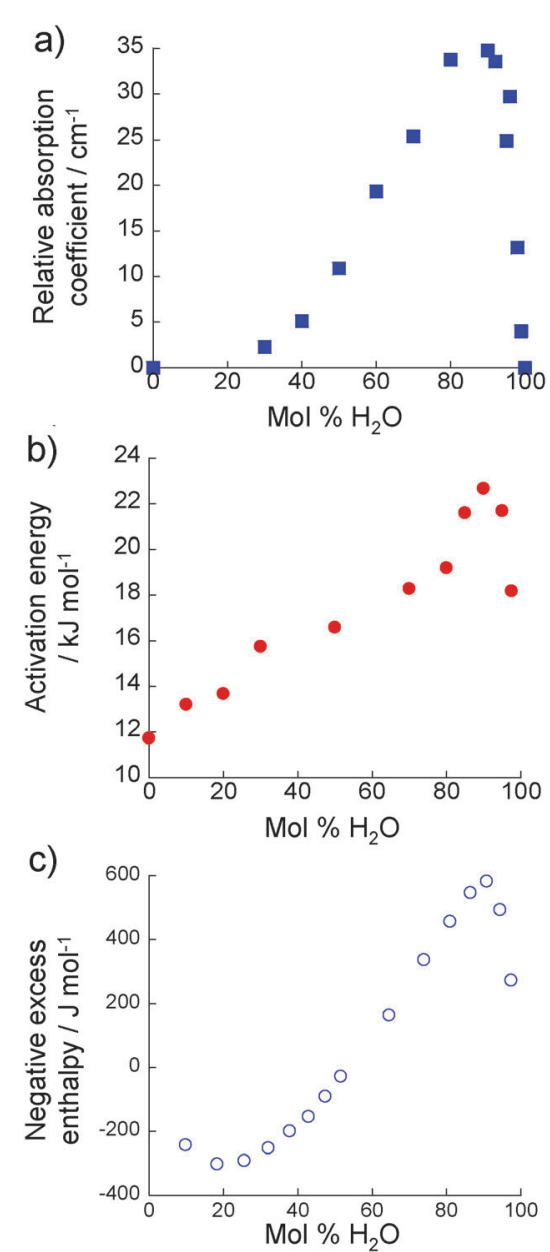

Fig. 5 (a) Relative absorption coefficient of 2-propanol/water mixtures (303 K) at $1 \mathrm{THz}$ as evaluated from THz-TDS measurements. (b) Activation energy for a molecular diffusive jump of 2-propanol in 2-propanol/water mixtures as determined using NMR relaxation time analysis. (c) Negative excess enthalpy associated with 2-propanol/water mixtures at $303 \mathrm{~K}$, from ref. 6 . diffusive jump, breaking its interaction with its neighbours and forming new interactions. These data are calculated for the alkyl group of the alcohol through NMR relaxation time analysis as described in Section 2.2. The observed trend closely mirrors that of $\alpha_{\text {ideal }}-\alpha_{\text {real }}$ (Fig. 5(a)) with a peak activation energy at $\sim 90 \mathrm{~mol} \% \mathrm{H}_{2} \mathrm{O}$. A higher activation energy corresponds to a molecule which is in a structurally more stable, long-lived environment. The NMR results, therefore, support the conclusions of THz-TDS that real solutions are more structured than ideal ones, as determined by the presence of extended alcohol-water hydrogen-bonded networks which are maximised at $~ 90 \mathrm{~mol} \%$ $\mathrm{H}_{2} \mathrm{O}$. The calculated activation energies fall within the limits 11.7-22.7 $\mathrm{kJ} \mathrm{mol}^{-1}$. These values are similar both to the energy of a $\mathrm{HB}$ in bulk water (reported to be between 12.6-33.5 $\mathrm{kJ} \mathrm{mol}^{-1}$ ) and to previously measured activation energies for the diffusion of solvated protons in water $\left(\sim 11 \mathrm{~kJ} \mathrm{~mol}^{-1}\right) .{ }^{13}$ For both 2-propanol and solvated protons this is a reflection that the diffusion process is driven by the breaking and formation of HBs. In order for 2-propanol to undergo a molecular diffusive jump it is necessary to break the HBs to the molecules around it, as indicated schematically in Fig. 1. A complete description of the environment of 2-propanol molecules in 2-propanol/water clusters is provided in Section 4.2.

3.3 Neutron diffraction and EPSR simulation. Neutron diffraction data and EPSR fits for the neat, 70 and $90 \mathrm{~mol} \%$ $\mathrm{H}_{2} \mathrm{O}$ systems are shown in Fig. 6. Good agreement was found between the experimental data and the EPSR-derived structure factors in all cases.

Molecule-molecule centre of mass radial distribution functions (RDFs) of 2-propanol/2-propanol, 2-propanol/water and water/water at the two compositions are shown in Fig. 7, and are compared with the corresponding RDF from neat 2-propanol. Overall, the RDF profiles at the two 2-propanol/water compositions are similar; however, there is a noticeable difference in the amplitude of the peak for the water-water partial RDF. This is largely a result of the decreased number density of water molecules in the $70 \mathrm{~mol} \% \mathrm{H}_{2} \mathrm{O}$ system, resulting in a stronger weighting of the corresponding RDFs.

The water-water near neighbour coordination number, however, (as determined from the integral under the curve between 0 and $3.4 \AA$ ) was $\sim 3.4$ for $70 \mathrm{~mol} \% \mathrm{H}_{2} \mathrm{O}$ and $\sim 3.9$ for $90 \mathrm{~mol} \% \mathrm{H}_{2} \mathrm{O}$ 2-propanol/water mixtures, and is a simple result of the lower alcohol concentration in the latter sample. The second broad peak centred around $\sim 4.5 \AA$, is characteristic of the hydrogen bonded network present in pure water which is largely preserved in both position and amplitude in both the 70 and $90 \mathrm{~mol} \% \mathrm{H}_{2} \mathrm{O}$ 2-propanol/water mixtures.

Fig. 8 shows the three oxygen-oxygen site-site RDFs from the two 2-propanol/water mixtures (70 and $90 \mathrm{~mol} \% \mathrm{H}_{2} \mathrm{O}$ ) and the corresponding $\mathrm{RDF}$ from neat 2-propanol. $\mathrm{O}$ denotes the oxygen atom of a 2-propanol molecule, while $\mathrm{O}_{\mathrm{W}}$ denotes the oxygen atom of a water molecule. Information about the local oxygen-oxygen structure, association, and the presence of hydrogen bonding networks in the mixtures can be determined through examination of these RDFs. In both mixtures, the relative profiles of the three RDFs are again similar, consistent 

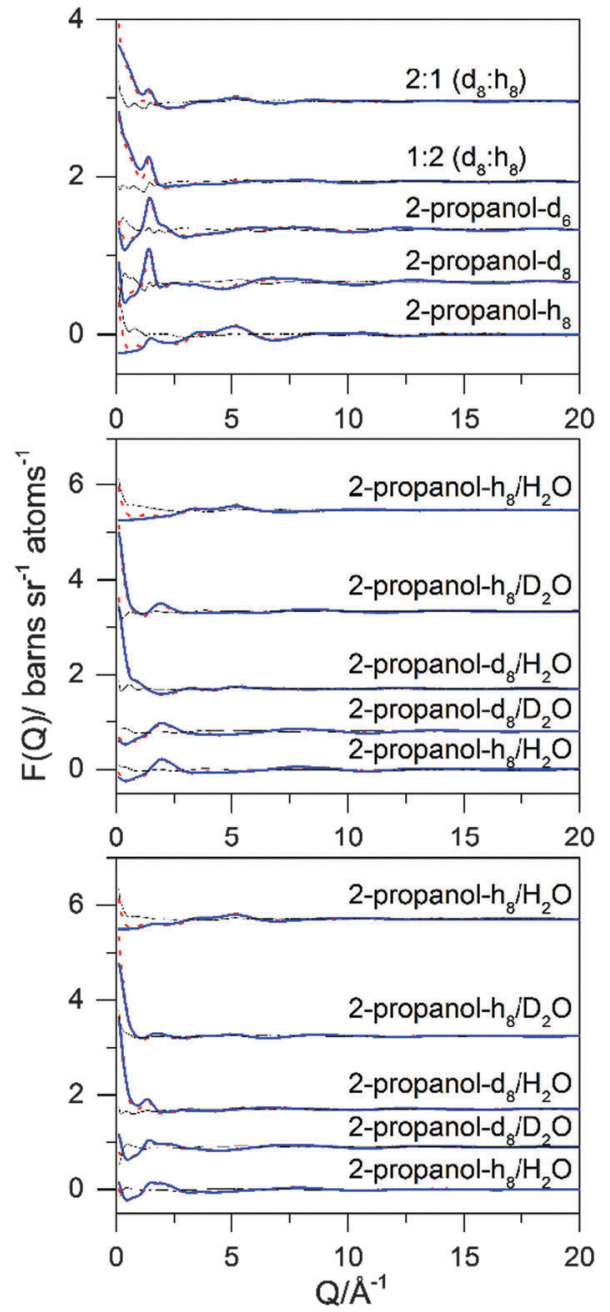

Fig. 6 Experimental (red dotted line), EPSR fitted (blue solid line) differential cross sections and the difference between them (black solid line) as a function of $Q$ for different isotopically substituted (a) neat 2-propanol, (b) $90 \mathrm{~mol} \% \mathrm{H}_{2} \mathrm{O}$, and (c) $70 \mathrm{~mol} \% \mathrm{H}_{2} \mathrm{O}$ 2-propanol/water mixtures.

with the total RDFs shown in Fig. 7. These indicate that there are no major changes in the local structuring around either the water or 2-propanol alcohol groups. The amplitude of the first peak of the $\mathrm{O}_{\mathrm{W}}-\mathrm{O}_{\mathrm{W}} \mathrm{RDF}$ for the $70 \mathrm{~mol} \% \mathrm{H}_{2} \mathrm{O}$ 2-propanol/water mixture is larger than the corresponding peak for the $90 \mathrm{~mol} \%$ $\mathrm{H}_{2} \mathrm{O}$ mixture; however, the position and shape are similar. The second-neighbour peaks (a signature of the hydrogen bonded network) for the $\mathrm{O}-\mathrm{O}$ and, to a lesser extent, the $\mathrm{O}-\mathrm{O}_{\mathrm{W}}$ RDFs are similar for both concentrations indicating no significant change in the extended network structure. Interestingly, a slightly better defined second shell is observed in the $\mathrm{O}_{\mathrm{W}}-\mathrm{O}_{\mathrm{W}}$ RDFs at the higher water concentration which may indicate a more structured water-water hydrogen bonded network.

\section{Discussion}

\subsection{Hydrogen bond dynamics}

The relative absorption coefficient (determined from the THzTDS analysis) and the activation energy for a molecular diffusive

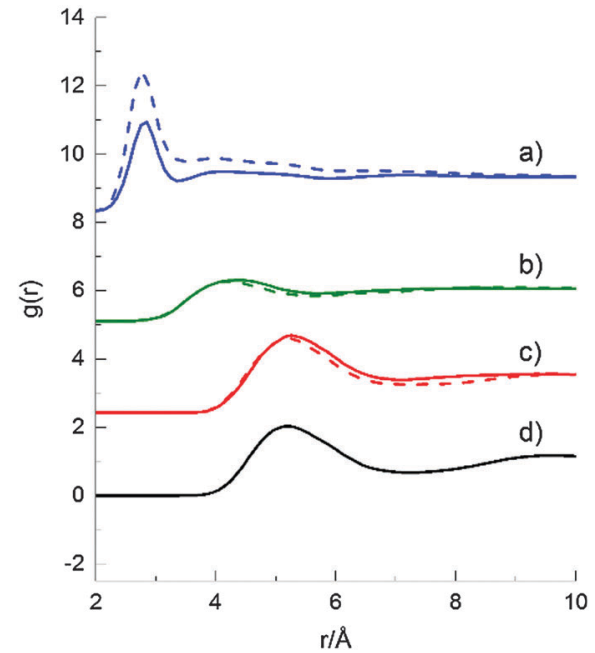

Fig. 7 Derived centre of mass molecule-molecule radial distribution functions for (a) water-water, (b) 2-propanol-water and (c) 2-propanol2-propanol (c) for 2-propanol/water mixtures at $70 \mathrm{~mol} \% \mathrm{H}_{2} \mathrm{O}$ (dashed lines) and 90 mol\% $\mathrm{H}_{2} \mathrm{O}$ (solid lines) compared with (d) neat 2-propanol.

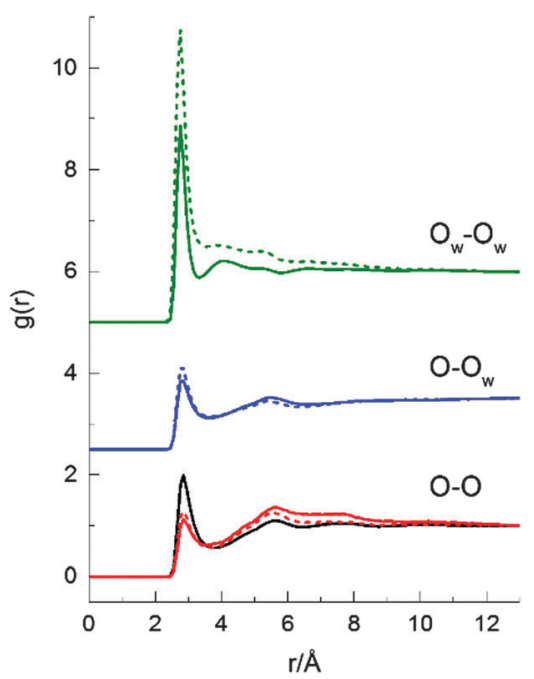

Fig. 8 The site-site oxygen-oxygen partial radial distributions, $\mathrm{O}_{W}-\mathrm{O}_{W}$ (green), $\mathrm{O}-\mathrm{O}_{\mathrm{W}}$ (blue) and $\mathrm{O}-\mathrm{O}$ (red), for $70 \mathrm{~mol} \% \mathrm{H}_{2} \mathrm{O}$ 2-propanol/water (dashed lines) and $90 \mathrm{~mol} \% \mathrm{H}_{2} \mathrm{O} 2$-propanol/water (solid lines) compared with neat 2-propanol O-O (black) at $298 \mathrm{~K}$ derived from the EPSR simulation.

jump of 2-propanol (determined form the NMR relaxation time analysis) both show maxima/minima at $\sim 90 \mathrm{~mol} \% \mathrm{H}_{2} \mathrm{O}$. Furthermore, this is also the concentration at which a maximum is observed in the negative excess enthalpy of 2-propanol/water mixtures (Fig. 5(c)). ${ }^{6}$ All these data show the same general profile as a function of composition; namely a slow increase as water concentration increases, reaching a maximum at $\sim 90 \mathrm{~mol} \% \mathrm{H}_{2} \mathrm{O}$, followed by a much more rapid decrease. Furthermore, the most rapid rate of change occurs at very low alcohol concentrations, at most a few percent. Other properties of alcohol/water solutions are also maximised or minimised at these low concentrations. For instance, excess acoustical absorption shows a similar 
concentration dependence, ${ }^{8,62}$ while Brillouin scattering measurements show a maximum sound velocity in water/1-propanol mixtures at $\sim 90 \mathrm{~mol} \% \mathrm{H}_{2} \mathrm{O} .{ }^{63}$ PFG-NMR data exhibit a minimum in the self-diffusivity of the alkyl chain of 2-propanol in water at $\sim 90 \mathrm{~mol} \% \mathrm{H}_{2} \mathrm{O}$ at $293 \mathrm{~K}^{15}$ A similar composition dependence is observed for Kamlet-Taft $\pi^{*}$ values which is a measure of polarisability. ${ }^{64}$ The rapid change at high water concentrations is an indication that, from a structural dynamic viewpoint, the solution rapidly becomes to resemble bulk water. This will have significant consequences in, e.g. facilitating proton transfer ${ }^{23}$ or the availability of water molecules, and therefore on any process or device which may depend on these. Examples of such processes include hydrogenation catalysis and protonexchange membranes. Here, the observation that the properties of the solution below $90 \mathrm{~mol} \% \mathrm{H}_{2} \mathrm{O}$ differ significantly from those of bulk water is supported by the results of complementary $a b$ initio molecular dynamics simulations. These show that proton transfer is $\sim 27$ times faster in pure water than in a $87 \mathrm{~mol} \% \mathrm{H}_{2} \mathrm{O}$ 2-propanol/water mixture. ${ }^{5}$ That proton transfer involves an extended network of water molecules and not simply those directly bound to the proton has been recently evidenced by THz-TDS, with $\sim 15$ water molecules calculated to be involved in such processes. ${ }^{23}$

The observation that the activation energy, relative absorption coefficient and excess enthalpy all correlate with each other can be assigned to the fact that all are related to HB dynamics. Excess enthalpy is essentially a measure of the average strength of intermolecular interactions. ${ }^{14}$ A higher magnitude of excess enthalpy therefore suggests stronger, more long-lived, HBs in the mixture, as do the more retarded dynamics evidenced by $\mathrm{THz}$ TDS and the higher activation to a molecular diffusive jump indicated by NMR. It is worth noting that neutron diffraction studies have previously shown that it is the strength, and not the number, of HBs that change on the addition of alcohol to pure water. ${ }^{17}$ The present study supports the conclusion that the ability of 2-propanol to interact with other molecules in solution is directly controlled by the hydrogen bonding structure of the mixture and the dynamics of those HBs. We now demonstrate in Section 4.2 that the size of these hydrogen bonded clusters is provided through an analysis of both THz-TDS and neutron diffraction data.

\subsection{Hydration shell analysis}

Analysis of the neutron diffraction data presented in Section 3.3 also allows for a quantitative analysis of the hydration shell around 2-propanol. For 70 and $90 \mathrm{~mol} \% \mathrm{H}_{2} \mathrm{O}$ 2-propanol/water mixtures, the coordination numbers found in the first shell for each of the centre-of-mass as well as the oxygen-hydrogen and the carbon-carbon partial RDFs are summarised in Table 1. These numbers are correlated with data for neat 2-propanol and water.

In the pure 2-propanol, the first-shell centre-of-mass coordination number is 11.9. In the mixed systems, the number of water molecules present in the first solvation shell of the 2-propanol molecules is found to increase with the mole fraction of water. A concomitant decrease in the number of 2-propanol
Table 1 Coordination numbers between 2-propanol and water sites calculated from integration of the relevant RDFs up to the position of the first minimum

\begin{tabular}{lllll}
\hline Radial distribution & $\begin{array}{l}70 \mathrm{~mol} \% \\
\text { function }\end{array}$ & $\begin{array}{l}90 \mathrm{~mol} \% \\
\mathrm{H}_{2} \mathrm{O}\end{array}$ & $\begin{array}{l}\mathrm{H}_{2} \mathrm{O} \\
\text { Neat }\end{array}$ & $\begin{array}{l}\text { Max } \\
\text { distance/Å }\end{array}$ \\
\hline Centre-of-mass & & & & \\
Water around water & 3.4 & 3.9 & - & 3.4 \\
2-Propanol around water & 2.7 & 1.4 & - & 5.8 \\
Water around 2-propanol & 6.2 & 12.4 & - & 5.6 \\
2-Propanol around 2-propanol & 8.6 & 4.4 & 11.9 & 7.2 \\
Water total & 6.1 & 5.3 & & \\
2-Propanol total & 14.8 & 16.8 & 11.9 & \\
& & & & \\
Oxygen-hydrogen partial RDF & & & & \\
Water around water & 2.5 & 3.2 & $3.6^{17}$ & 2.4 \\
2-Propanol around water & 0.4 & 0.2 & - & 2.5 \\
Water around 2-propanol & 1.0 & 1.4 & - & 2.5 \\
2-Propanol around 2-propanol & 0.4 & 0.2 & 0.9 & 2.7 \\
Water total & 2.9 & 3.4 & $3.6^{17}$ & \\
2-Propanol total & 1.4 & 1.6 & 0.9 & \\
& & & & \\
Carbon-carbon partial RDF & & & & \\
Methyl C around methyl C & 6.7 & 3.4 & 9.2 & 4.7 \\
\hline
\end{tabular}

molecules is also found, highlighting the replacement of the alcohol by water in the first solvation shell of the alcohol. Each 2-propanol is replaced by 1.9 and 1.7 water molecules in the 70 and $90 \mathrm{~mol} \% \mathrm{H}_{2} \mathrm{O}$ systems, respectively. This difference is a reflection of the non-ideal mixing in the present systems. In a similar manner, the solvation shell around water is perturbed in going from the lower to higher concentration of 2-propanol, with the number of resident water molecules reduced, and the number of alcohol molecules doubled. The environment of the first coordination shell around water is able to accommodate the 2-propanol molecules relatively easily. Due to the bulky nature of the alcohol this suggests that this is via hydrogen bonding, rather than simple incorporation of the methyl groups into the shell.

Despite a centre-of-mass coordination number of 11.9 in pure 2-propanol, integration of the $\mathrm{O}-\mathrm{H}$ partial RDFs up to the first minimum (in line with the analysis of Dixit et al. $)^{17}$ reveals that only 0.9 hydrogen bond contacts are formed by the oxygen at the centre. This compares with a value of 1.8 calculated for methanol, and is consistent with the bulkier nature of the aliphatic group in the present case. Herein, the predominant type of contact between 2-propanol molecules is between methyl groups. In fact, an examination of the $\mathrm{C}-\mathrm{C}$ partial radial distribution function (see ESI, $\uparrow$ Fig. S1) show a methyl-methyl coordination number of 9.2, integrating up to $4.7 \AA$ A. Coordination numbers from the mixed systems show that hydrogen bonding between 2-propanol molecules is significantly reduced by the presence of the water, with only 0.2 remaining in the case of the lower concentration of alcohol. Clearly, hydrogen bonding with water is more favourable, with 1.0 and 1.4 contacts formed between the 2-propanol $\mathrm{OH}$ group and the water in the 70 and $90 \mathrm{~mol} \%$ systems, respectively, of which approximately $35 \%$ are attributable to the 2-propanol acting as the $\mathrm{H}$-bond donor. In line with this, the number of hydrogen bonds between water molecules reduces from 3.2 to 2.5 on moving to the lower 
mol\% $\mathrm{H}_{2} \mathrm{O}$ system which can be compared with 3.6 molecules in the pure water system. ${ }^{17}$

Using values of 0.9 and $3.6^{17}$ hydrogen bonds in pure 2-propanol and water, respectively, the expected number of hydrogen bonds per molecule in the $90 \mathrm{~mol} \% \mathrm{H}_{2} \mathrm{O}$ mixture is calculated as 3.3, assuming ideal mixing between the two species, while for $70 \mathrm{~mol} \% \mathrm{H}_{2} \mathrm{O}$ mixture the expected number is 2.8. From the discussion above we can see that the overall number of hydrogen bonds each 2-propanol $\mathrm{OH}$ group is involved in increases on the addition of water into the system. The inference from these data is that hydrogen bonding contacts between alcohol molecules are reduced in favour of contacts with water molecules, and this is reflected in the increased number of water molecules in the primary coordination shell. The net result of this is that, while the number of hydrogen bonding contacts between 2-propanol molecules decreases, the overall number increases significantly due to additional interactions with water molecules. In terms of contacts between hydrophobic groups, even in the $90 \mathrm{~mol} \% \mathrm{H}_{2} \mathrm{O}$ system there is still significant clustering of methyl groups, with the relevant coordination number calculated as 3.4.

The hydrogen bonding network in such a system is not quantified easily by simple coordination numbers. Calculations of clusters sizes formed from continuous $\mathrm{O}-\mathrm{O}$ contacts between molecules of less than $3.1 \AA$ suggest that in neat 2-propanol $\sim 40 \%$ of alcohol molecules are, at any one instant, isolated and not participating in hydrogen bonding with other alcohol molecules. In the $70 \mathrm{~mol} \% \mathrm{H}_{2} \mathrm{O}$ mixture this rises to $\sim 56 \%$, and in the $90 \mathrm{~mol} \% \mathrm{H}_{2} \mathrm{O}$ to $77 \%$, again confirming the breakup of 2-propanol clusters by the water. Combined with the coordination numbers of methyl groups, this suggests a picture of 2-propanol molecules that tend not to interact with each other via hydrogen bonding, but instead tend to cluster through closecontacts with their methyl groups, thus minimising hydrophobic contacts with the solvent.

Fig. 9 shows the spatial probability densities of 2-propanol and water around a central 2-propanol. In neat 2-propanol we observe that the oxygen atoms of the alcohol favour the region around the $\mathrm{OH}$ group, and the methyl carbons tend to aggregate at the hydrophobic end of the molecule - this is clearly related to 2-propanol - .2-propanol hydrogen bonding. In comparison to the neat system, a decrease in alcohol-alcohol coordination through the O-atom is observed in the aqueous alcohol mixtures, with the lobe of oxygen atom density disappearing. Nevertheless, the density associated with the methyl carbons persists. Hydrogen bond formation with water is evidenced by the distinct halo of high probability circling the 2-propanol $\mathrm{OH}$ group. The decrease in the 2-propanol $\mathrm{OH}-\mathrm{OH}$ coordination, can be ascribed to increased competition from water for the 2-propanol $\mathrm{OH}$ group, which occurs through the insertion of water at the shorter distances causing disruption of the alcohol-alcohol probability distribution (Fig. 9).

At both 70 and $90 \mathrm{~mol} \% \mathrm{H}_{2} \mathrm{O}$ concentrations, the 2-propanol $\mathrm{OH}$ groups experience a heterogeneous environment in which they interact with both 2-propanol and water species. The ratio between the number of hydrogen bonds formed by water and 2-propanol molecules to a central alcohol molecule decreases a)

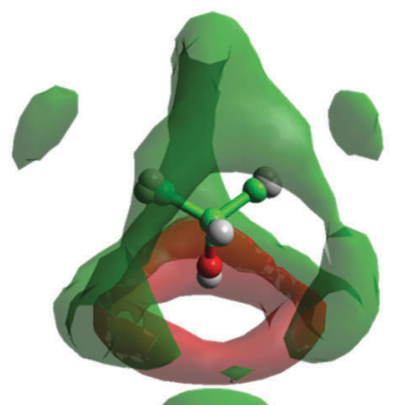

b)
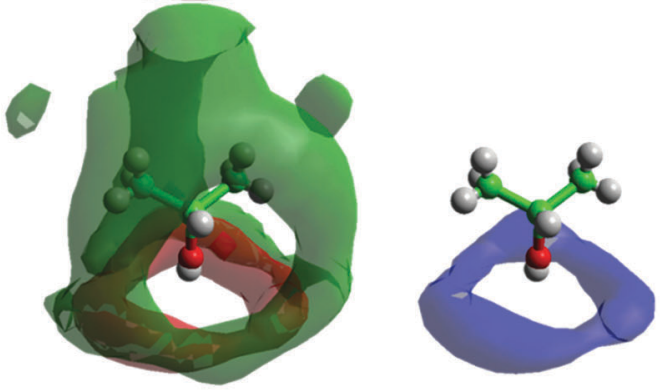

c)
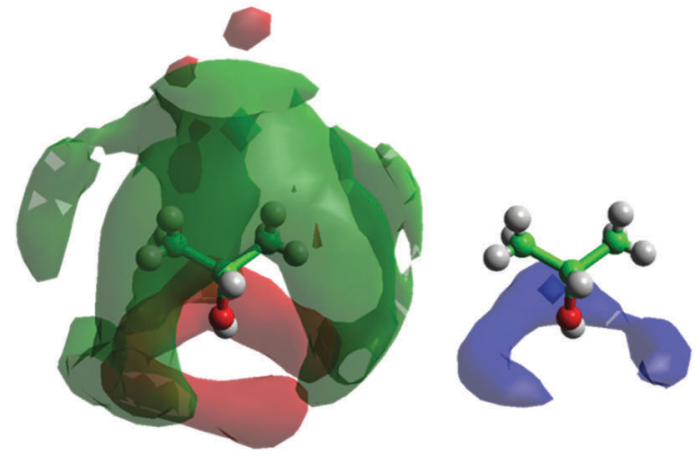

Fig. 9 Spatial probability densities of 2-propanol (methyl group distribution - green; oxygen - red) and water (blue) showing $50 \%$ of all points collected for each simulation box up to the first minimum of the corresponding RDF and a cutoff of $4 \rho$ for methyl group distribution, $2 \rho$ for oxygen distribution and $2 \rho$ for water distribution, where $\rho$ is the corresponding number density, in (a) neat 2-propanol and (b) 70 mol\% $\mathrm{H}_{2} \mathrm{O}$ and (c) 90 mol\% $\mathrm{H}_{2} \mathrm{O}$ 2-propanol/ water mixtures. Graphs have been plotted using Aten. ${ }^{66}$

from $7.0: 1$ at $90 \mathrm{~mol} \% \mathrm{H}_{2} \mathrm{O}$ to $2.5: 1$ at the lower water concentration. These values compare with ratios of $9.0: 1$ and 2.3:1 at 90 and $70 \mathrm{~mol} \% \mathrm{H}_{2} \mathrm{O}$, respectively, based on the stoichiometric composition of the mixtures, i.e. ideal mixing. These results indicate that, at the higher concentration of 2-propanol, the system is relatively well-mixed with the relative ratio of hydrogen bonds formed depending on the composition of the mixture. However, for the $90 \mathrm{~mol} \% \mathrm{H}_{2} \mathrm{O}$ system the ratio is slightly lower than expected, indicating a higher number of H-bond contacts formed between 2-propanol molecules than would be expected based on purely stoichiometric arguments, and suggests more clustering of alcohol molecules at the lower concentration. The role of hydrophobic methyl-methyl interaction in these mixtures should not be discounted, and will play an important role in stabilising small clusters.

The size of the hydration shell formed around 2-propanol molecules at $90 \mathrm{~mol} \% \mathrm{H}_{2} \mathrm{O}$ has been calculated from THz-TDS analysis as previously described, ${ }^{15}$ based on the number ratio 
between water and 2-propanol molecules in the hydrogen-bonded network, and shows a value of $5.0 \pm 0.2$ water molecules per 2-propanol. The neutron results, however, indicate that only 1.4 water molecules are hydrogen bonding to each 2-propanol at any given time. Furthermore, the value of 12.4 calculated from the centre-of-mass RDFs is also significantly different, and leads to the question of what precisely is being probed by the experimental analysis. To clarify this, the mean number of water molecules around 2-propanol $\mathrm{OH}$ groups, formed through hydrogen bond networks has been calculated from the neutron data.

Enforcing a maximum distance of $2.45 \AA$ for the hydrogen bond, and allowing at most two 'jumps' from the originating alcohol moiety, we calculate numbers of 2.2 and 4.1 for the 70 and $90 \mathrm{~mol} \%$ water systems, respectively. These numbers reflect the total number of water molecules that are either hydrogen bonding directly to a given 2-propanol $\mathrm{OH}$ group, or are hydrogen bonding to one of these primary molecules. This therefore represents those solvent molecules that are directly or strongly associated with the alcohol $\mathrm{OH}$ group. In particular, the value of 4.1 agrees well with that obtained from THz-TDS analysis, suggesting that the experimental technique is in fact probing this extended water neighbourhood. Interestingly, this analysis reveals that around one third of the 2-propanol molecules in the $30 \mathrm{~mol} \%$ water system are not directly bound to any water molecules (given the distance criterion above). For the $90 \mathrm{~mol} \%$ water system the percentage of alcohol molecules not hydrogen bonding to any water molecules is considerably smaller at around $16 \%$, and reflects the better mixing present in the case of higher water mole fraction.

The results reported herein, correlate well with other analyses of alcohol-water clusters. For instance, through neutron diffraction studies Dixit and co-workers ${ }^{17}$ identified that methanol molecules in aqueous solution formed 2.0 hydrogen bonds at a concentration of $30 \mathrm{~mol}^{2} \mathrm{H}_{2} \mathrm{O}$, while at $70 \mathrm{~mol} \% \mathrm{H}_{2} \mathrm{O}$ Bakó et al. determined a value of $2.2 \mathrm{HBs}$ in methanol/water clusters. ${ }^{65}$ Elsewhere, Bowron and co-workers showed that addition of as little as $0.14 \mathrm{~mol} \%$ of water to tertiary butanol transformed the neat alcohol structure to that of bulk alcohol/water mixtures through formation of preferential hydrogen-bonding of alcohol OH-groups to water. ${ }^{39-42}$ Similarly, Misawa et al. interpreted the structure of 1-propanol/water in terms of intercalating clusters with the bulk of both alcohol and water molecules existing at the interfaces, where one would anticipate a greater degree of interaction, i.e. hydrogen-bonding. 2-propanol is a significantly larger molecule than methanol and hence can be expected to have a larger hydration shell. ${ }^{38}$ Previously, we have shown that THz-TDS analysis of the ratio of methanol to water molecules in methanol/ water mixtures is in good agreement with literature data. ${ }^{15}$

\section{Conclusions}

Excellent agreement has been observed between the relative absorption coefficient as measured by THz-TDS, activation energy to molecular diffusive jumps as measured by NMR relaxation time analysis and excess thermodynamic function data. This agreement extends to the value at which the observed maxima occur, i.e. $\sim 90 \mathrm{~mol}^{\circ} \mathrm{H}_{2} \mathrm{O}$, and the shape of the curves as a function of composition. All of these parameters are directly related to $\mathrm{HB}$ dynamics and the presence of mixed 2-propanol/water networks which persist over the entire composition range. Neutron diffraction data provide evidence of the aggregation of the 2-propanol and water molecules. These aggregates are stabilised by the hydrogen bonding network. In addition, good agreement is found for the composition of the aggregates determined by THz-TDS and neutron scattering analysis, albeit with a reasonably high error from the latter due to the difficulty in determining the radial distribution cutoff distance. Both techniques indicate that the ratio of water to 2-propanol molecules in mixed 2-propanol/water aggregates at a composition of $90 \mathrm{~mol} \% \mathrm{H}_{2} \mathrm{O}$ is between $4-5: 1$. The liquid structuring observed in the present work will impact on physical or chemical processes occurring in 2-propanol/water mixtures. A specific example of this is explored in a parallel work where such mixtures are used as the solvent in the heterogeneous catalytic hydrogenation of 2-butanone. ${ }^{5}$ The dependence of reaction rate on solvent composition is discussed therein.

\section{Acknowledgements}

The authors would like to acknowledge CASTech (EPSRC grant EP/G011397/1), RCUK Basic Technology Grant (EP/E048811/1), STFC for beamtime allocation (RB910286) and Jon Mitchell (Cambridge) for valuable discussions.

\section{Notes and references}

1 C. Corsaro, J. Spooren, C. Branca, N. Leone, M. Broccio, C. Kim, S. H. Chen, H. E. Stanley and F. Mallamace, J. Phys. Chem. B, 2008, 112, 10449-10454.

2 D. R. Palo, R. A. Dagle and J. D. Holladay, Chem. Rev., 2007, 107, 3992-4021.

3 P. Kumar, Z. Yan, L. Xu, M. G. Mazza, S. V. Buldyrev, S. H. Chen, S. Sastry and H. E. Stanley, Phys. Rev. Lett., 2006, 97, 177802.

4 S. H. Chen, L. Liu, E. Fratini, P. Baglioni, A. Faraone and E. Mamontov, Proc. Natl. Acad. Sci. U. S. A., 2006, 103, 9012-9016.

5 B. S. Akpa, C. D’Agostino, L. F. Gladden, K. Hindle, J. McGregor, H. Manyar, R. Li, M. Neurock, D. W. Rooney, N. Sinha, E. H. Stitt, D. Weber and J. A. Zeitler, J. Catal., 2012, 289, 30-41.

6 J. R. Battler, W. M. Clark and R. L. Rowley, J. Chem. Eng. Data, 1985, 30, 254-259.

7 K. Soliman and E. Marschall, J. Chem. Eng. Data, 2002, 35, 375-381.

8 M. Akramova, O. Shokirow and T. Nurtidinov, Dokl. Akad. Nauk Tadzh. SSR, 1976, 19, 27-30.

9 Z. J. Derlacki, A. J. Easteal, A. V. J. Edge, L. A. Woolf and Z. Roksandic, J. Phys. Chem., 1985, 89, 5318-5322.

10 N. Micali, S. Trusso, C. Vasi, D. Blaudez and F. Mallamace, Phys. Rev. E: Stat. Phys., Plasmas, Fluids, Relat. Interdiscip. Top., 1996, 54, 1720-1724.

11 D. S. Venables and C. A. Schmuttenmaer, J. Chem. Phys., 2000, 113, 11222-11236. 
12 L. Dougan, R. Hargreaves, S. P. Bates, J. L. Finney, V. Reat, A. K. Soper and J. Crain, J. Chem. Phys., 2005, 122, 174514.

13 H. Lapid, N. Agmon, M. K. Petersen and G. A. Voth, J. Chem. Phys., 2005, 122, 014506.

14 T. Sato and R. Buchner, J. Chem. Phys., 2003, 119, 10789-10800.

15 R. Li, C. D’Agostino, J. McGregor, M. D. Mantle, J. A. Zeitler and L. F. Gladden, J. Phys. Chem. B, 2014, 118, 10156.

16 H. S. Frank and M. W. Evans, J. Chem. Phys., 1945, 13, 507-532.

17 S. Dixit, J. Crain, W. C. K. Poon, J. L. Finney and A. K. Soper, Nature, 2002, 416, 829-832.

18 L. Dougan, S. P. Bates, R. Hargreaves, J. P. Fox, J. Crain, J. L. Finney, V. Reat and A. K. Soper, J. Chem. Phys., 2004, 121, 6456-6462.

19 A. K. Soper, L. Dougan, J. Crain and J. L. Finney, J. Phys. Chem. B, 2006, 110, 3472-3476.

20 P. A. Artola, A. Raihane, C. Crauste-Thibierge, D. Merlet, M. Emo, C. Alba-Simionesco and B. Rousseau, J. Phys. Chem. B, 2013, 117, 9718.

21 I. Juurinen, T. Pylkkanen, C. J. Sahle, L. Simonelli, K. Hämäläinen, S. Huotari and M. Hakala, J. Phys. Chem. B, 2014, 118, 8750.

22 D. S. Venables and C. A. Schmuttenmaer, J. Chem. Phys, 1998, 108, 4935-4944.

23 K. J. Tielrooij, R. L. A. Timmer, H. J. Bakker and M. Bonn, Phys. Rev. Lett., 2009, 102, 198303.

24 D. A. Schmidt, Ö. Birer, S. Funkner, B. P. Born, R. Gnanasekaran, G. W. Schwaab, D. M. Leitner and M. Havenith, J. Am. Chem. Soc., 2009, 131, 18512-18517.

25 M. Heyden, E. Bründermann, U. Heugen, G. Niehues, D. M. Leitner and M. Havenith, J. Am. Chem. Soc., 2008, 130, 5773-5779.

26 U. Heugen, G. Schwaab, E. Bründermann, M. Heyden, X. Yu, D. M. Leitner and M. Havenith, Proc. Natl. Acad. Sci. U. S. A., 2006, 103, 12301-12306.

27 B. Born, H. Weingärtner, E. Bründermann and M. Havenith, J. Am. Chem. Soc., 2009, 131, 3752-3755.

28 S. Ebbinghaus, S. J. Kim, M. Heyden, X. Yu, U. Heugen, M. Gruebele, D. M. Leitner and M. Havenith, Proc. Natl. Acad. Sci. U. S. A., 2007, 104, 20749-20752.

29 B. Born, S. J. Kim, S. Ebbinghaus, M. Gruebele and M. Havenith, Faraday Discuss., 2009, 141, 161-173.

30 M. Nakahara, C. Wakai, Y. Yoshimoto and N. Matubayasi, J. Phys. Chem., 1996, 100, 1345-1349.

31 K. T. Gillen, M. Schwartz and J. H. Noggle, Mol. Phys., 1971, 20, 599.

32 S. Godefroy, M. Fleury, F. Deflandre and J. P. Korb, J. Phys. Chem. B, 2002, 106, 11183-11190.

33 N. Bloembergen, E. M. Purcell and R. V. Pound, Phys. Rev., 1948, 73, 679-712.

34 Y. Tanaka, N. Ohtomo and K. Arakawa, Bull. Chem. Soc. Jpn., 1984, 57, 644-647.

35 P. Zetterstrom, U. Dahlborg, R. G. Delaplane and W. S. Howells, Phys. Scr., 1991, 44, 56-62.

36 D. G. Montague, I. P. Gibson and J. C. Dore, Mol. Phys., 1981, 44, 1355-1367.

37 T. Takamuku, K. Saisho, S. Aoki and T. Yamaguchi, Z. Naturforsch., A: Phys. Sci., 2002, 57, 982-994.
38 M. Misawa, I. Dairoku, A. Honma, Y. Yamada, T. Sato, K. Maruyama, K. Mori, S. Suzuki and T. Otomo, J. Chem. Phys., 2004, 121, 4716-4723.

39 D. T. Bowron, A. K. Soper and J. L. Finney, J. Chem. Phys., 2001, 114, 6203-6219.

40 D. T. Bowron and S. D. Moreno, J. Chem. Phys., 2002, 117, 3753-3762.

41 D. T. Bowron and S. D. Moreno, J. Phys.: Condens. Matter, 2003, 15, S121-S127.

42 J. L. Finney, D. T. Bowron and A. K. Soper, J. Phys.: Condens. Matter, 2000, 12, A123-A128.

43 E. P. J. Parrott, J. A. Zeitler, T. Friščić, M. Pepper, W. Jones, G. M. Day and L. F. Gladden, Cryst. Growth Des., 2009, 9, 1452-1460.

44 T. Sato and R. Buchner, J. Chem. Phys., 2003, 118, 4606-4613. 45 E. Fukushima and S. B. W. Roeder, Experimental Pulse NMR, A Nuts and Bolts. Approach, Perseus Books, Reading, Massachusetts, 1981, p. 147.

46 Y. Zhou, K. Hu, J. Shen, X. Wu and G. Cheng, J. Mol. Struct., 2009, 921, 150-155.

47 R. L. Vold, J. S. Waugh, M. P. Klein and D. E. Phelps, J. Chem. Phys., 1968, 48, 3831-3832.

48 A. K. Soper, W. S. Howells and A. C. Hannon, ATLAS Analysis of Time of Flight Diffraction Data from Liquid and Amorphous Samples, Rutherford Appleton Laboratory, 1989.

49 A. C. Hannon, W. S. Howells and A. K. Soper, Inst. Phys. Conf. Ser., 1990, 107, 193-211.

50 A. K. Soper, Chem. Phys., 1996, 202, 295-306.

51 A. K. Soper, Chem. Phys., 2000, 258, 121-137.

52 A. K. Soper, Mol. Phys., 2001, 99, 1503-1516.

53 T. G. A. Youngs, dlputils, version 1.3.9, http://www.projecta ten.net/dlputils (accessed May 2015).

54 W. L. Jorgensen and J. Tirado-Rives, J. Am. Chem. Soc., 1988, 110, 1657-1666.

55 H. J. C. Berendsen, J. R. Grigera and T. P. Straatsma, J. Phys. Chem., 1987, 91, 6269-6272.

56 M. Koeberg, C. C. Wu, D. Kim and M. Bonn, Chem. Phys. Lett., 2007, 439, 60-64.

57 K. J. Tielrooij, D. Paparo, L. Piatkowski, H. J. Bakker and M. Bonn, Biophys. J., 2009, 97, 2484-2492.

58 C. Rønne, L. Thrane, P.-O. Åstrand, A. Wallqvist, K. V. Mikkelsen and S. R. Keiding, J. Chem. Phys., 1997, 107, 5319-5331.

59 G. D’Arrigo and J. Teixeira, J. Chem. Soc., Faraday Trans., 1990, 86, 1503-1509.

60 I. Shulgin and E. Ruckenstein, J. Phys. Chem. B, 1999, 103, 872-877.

61 S. J. Suresh and V. M. Naik, J. Chem. Phys., 2000, 113, 9727-9732.

62 O. N. Awasthi and S. Sathish, Indian J. Pure Appl. Phys., 1978, 16, 489-491.

63 Y. Seshimo, Y. Ike and S. Kojima,Jpn. J. Appl. Phys., 2008, 47, 3836-3838.

64 W. J. Cheong and P. W. Carr, Anal. Chem., 1988, 60, 820-826. 65 I. Bakó, T. Megyes, S. Balint, T. Grosz and V. Chihaia, Phys. Chem. Chem. Phys., 2008, 10, 5004-5011.

66 T. G. A. Youngs, J. Comput. Chem., 2010, 31, 639-648. 